Document downloaded from:

http://hdl.handle.net/10251/140978

This paper must be cited as:

Bugge, M.; Coenen, L.; Marques, P.; Morgan, K. (2017). Governing system innovation: assisted living experiments in the UK and Norway. European Planning Studies. 25(12):21382156. https://doi.org/10.1080/09654313.2017.1349078

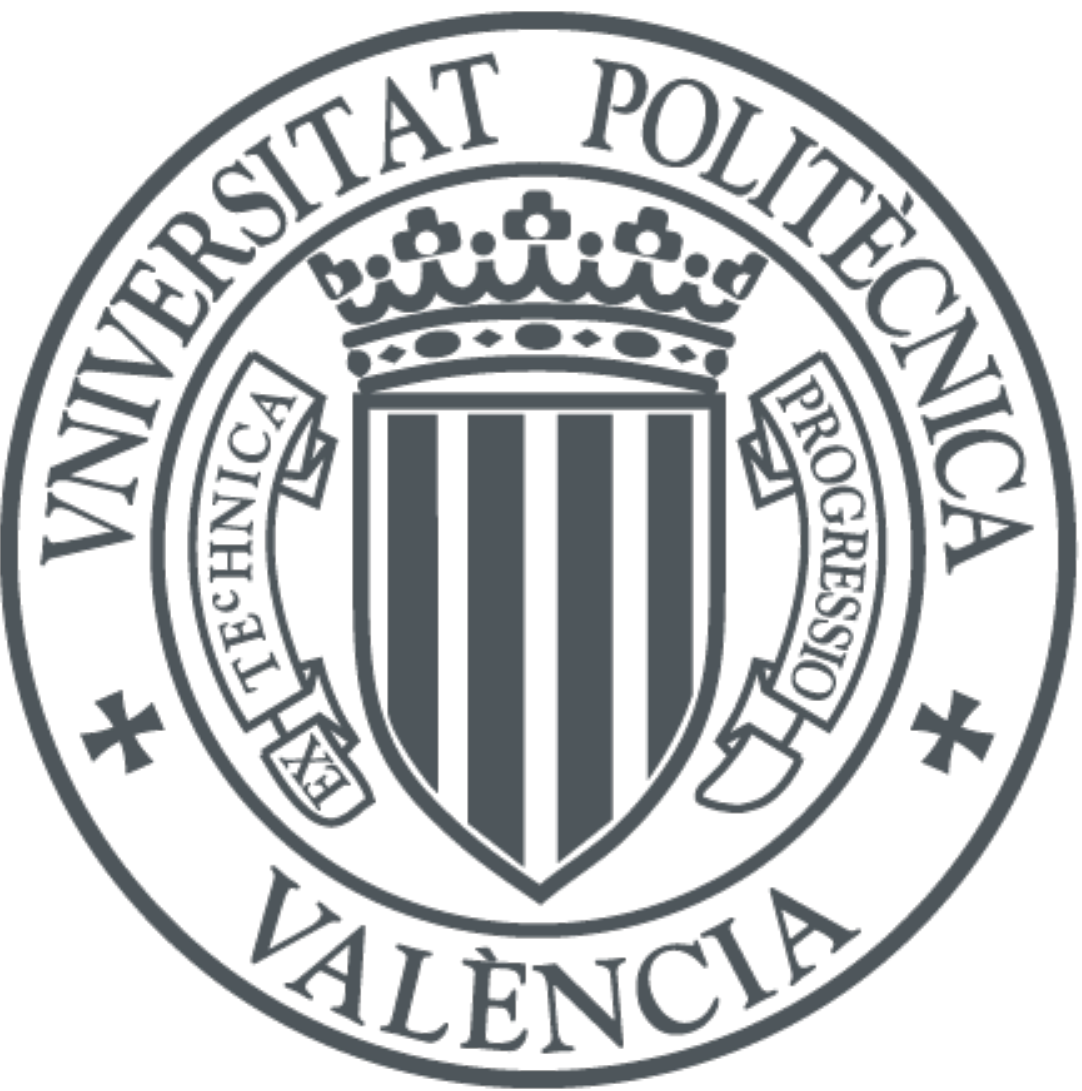

The final publication is available at

https://doi.org/10.1080/09654313.2017.1349078

Copyright Taylor \& Francis

Additional Information 


\title{
Governing System Innovation: Assisted Living Experiments in the UK and Norway
}

Markus Bugge: NIFU Nordic Institute for Studies in Innovation, Research and Education, Oslo, Norway

Lars Coenen: Melbourne Sustainable Society Institute, The University of Melbourne, Parkville, Victoria, Australia; CIRCLE, Centre for Innovation, Research and Competence in the Learning Economy, Lund University, Lund, Sweden

Pedro Marques: INGENIO (CSIC-UPV), Universitat Politècnica de València, Valencia, Spain

Kevin Morgan: School of Geography and Planning, Cardiff University, Cardiff, UK

Version accepted for publication at European Planning Studies:

http://www.tandfonline.com/doi/full/10.1080/09654313.2017.1349078

\begin{abstract}
Debates on how to address societal challenges have moved to the forefront of academic and policy concerns. Of particular importance is the growing awareness that to deal with issues such as ageing, it will be necessary to implement concerted efforts on technological, social, institutional or political fronts. Drawing on a number of theoretical perspectives - including socio-technical transitions and embedded state theory - the aim of this paper is to identify and understand different approaches to the governance of such system innovations by comparing state responses to assisted living in two contrasting national systems of care, namely that of the UK and Norway. Its findings highlight that state-supported and funded experimentation projects have been instrumental in designing and implementing system innovation: through their emphasis on co-design and co-creation, these projects demonstrated the value of early implementation pilots to explore the 'fit' between novel technologies and prevailing practices and institutional structures in national systems of care. Still, competition, biases or conflicting interests should not be ignored between well-established agents and institutions and experimental solutions whose efficacy remains relatively untested and which involve a combination of new technical, social, organizational and institutional solutions.
\end{abstract}




\section{Introduction}

The field of innovation studies is in a state of flux as new and more capacious concepts are beginning to appear, taking the field way beyond its original focus on science and technology (Martin 2015). In the past decade we have witnessed the growth of a voluminous literature addressed to ecological innovation, social innovation, grassroots innovation and responsible research and innovation, all of which are cause and consequence of a new interest in grand or societal challenges and mission-led research and innovation. Arguably the most aspirational and complex forms of innovation fall under the category of system innovation, which is "a concept used to illustrate a horizontal policy approach that mobilises technology, market mechanisms, regulations and social innovations to solve complex societal problems in a set of interacting or interdependent components that form a whole socio-technical system” (OECD 2015:6).

Conventional models of innovation based on a Science, Technology, Innovation paradigm (Jensen et al 2007) are considered insufficient to address the system innovations that the new societal challenges and mission-led agenda seem to imply (Steward 2012). First, the scale of the interdependencies between state, market and civil society is so much greater than hitherto acknowledged, underlining the heightened importance of the "cooperative component of entrepreneurship” (Hirschman, 1958:19). Second, firms are merely one type of agent in the new landscape because the "democratization" of innovation signals the rise of a whole series of new agents of innovation, not least users, citizens, municipalities and NGOs among others (Seyfang and Smith 2007). Thirdly, the state looms larger in the new landscape because its multiple roles - as regulator, producer, purchaser, financier, animateur and so forth - have an enormous impact across all the societal challenge areas. So much so that it effectively fashions the socioeconomic environment in which innovation occurs and this raises large questions about the competence, coherence and convening capacity of public bodies (Morgan 2016). 
A key driver of this growing interest in system innovation is Horizon 2020, the research and innovation programme of the EU, which plans to commit nearly 80 billion euro to three R\&I pillars, including one dedicated to Societal Challenges. The first of these Societal Challenges is framed as Health, Demographic Change and Wellbeing and among other things, it aims to support the Active and Healthy Ageing agenda, one of the key strands of which is Assisted Living. This Societal Challenge corresponds to a number of systemic pressures that welfare states and respective forms of public service provision are facing. However, although the EC frames the Active and Healthy Ageing Agenda in broad European terms, the single most significant feature of welfare state services is the fact that they are profoundly national in their institutional structure and political culture. This picture becomes further complicated as policy domains such as health, research and innovation are devolved to sub-national levels such as regions and municipalities.

The aim of this paper is to identify and understand different approaches to governing system innovations, drawing on theorizing on strategic niche management (SNM), embedded state and transformational system failures and comparing state responses to assisted living in two national systems of care, namely that of the UK and Norway. The research question guiding the paper can be summarized as follows: How do state responses to system innovation in health care vary across national contexts? The remainder of the paper proceeds as follows. Section two outlines the theoretical framework. Section three presents the methodology, before section four provides the national contexts of the UK and Norway in what concerns health policies for the elderly. Section five discusses our two case studies in detail, and section six sums up the findings. Finally, section seven concludes on what our empirical data means in conceptual terms.

\section{Conceptual framework: the role of the state in strategic niche management}

The concept of socio-technical transitions has gained ground as a lens through which major system transformations and innovations can be analysed (OECD 2015). The strength of this 
concept lies in its capacity to stress the interdependence of technological, social, cultural and political dimensions, and the way in which change in one of these dimensions implies adjustments in the others (Smith et al 2010). In the context of this paper it will be deployed to analyse the societal challenge of ageing populations. This challenge involves multiple dimensions, including the sustainability of public finances, the creation of new technological and medical devices to deal with longer life-spans, or the organization and financing of care services for the elderly (Tinker et al 2013, Mace 2014).

One of the main questions for those concerned with socio-technical transitions regards the emergence of new technologies and respective restructuring of practices, organizations and institutions in the context of relatively stable regimes. Here, a regime refers to an entrenched socio-technical system whose specific institutional logic structures perception and behaviour of actors, thus favouring path-dependent incremental change and impeding large scale change (Geels 2002). Changes to any given regime are thought to emerge primarily from activities at the niche level, and which under certain conditions have the potential to generate system transformation (Schot and Geels 2008; Smith et al 2010).

A niche is defined as an 'incubation space' for radically new technologies and/or practices characterized by high technological, institutional and market uncertainty. The function of niches is to protect radical innovations against market selection and institutional pressures from an existing regime and to allow actors to learn about these novelties and their uses through experimentation (Coenen et al 2010). System transformation is believed to occur when niches gather sufficient momentum so that these relatively loose configurations become institutionalized and create capacity for emergent technologies and practices to challenge and re-institutionalize a regime.

One means by which system innovations are thought to proceed is through SNM, Strategic Niche Management (Kemp et al 1998) - whereby governments, or other actors, deliberately 
seek to establish conditions under which niches for innovation can grow and 'break through' existing regime conditions. Importantly, despite a rather unfortunate and misleading allusion to 'management ${ }^{1 \text { ' }}$ this approach emphasizes entrepreneurial experimentation as a means to govern system innovation rather than centralized control (Bulkeley et al 2012). Entrepreneurial experimentation suggests that "linking knowledge and its societal use is often a trial-and-error process in which existing knowledge is used and combined, new knowledge is created, suitable routines are elaborated upon, market opportunities are screened and combinations of knowledge, routines, and markets are tested and continually adapted” (Benner 2014, p. 42).

Here it posits a generous conception of entrepreneurial activity, so much so that it is located not just in firms but in a wide array of other agents and institutions, including users, universities and actors in the public sector, such as municipalities, state agencies, public laboratories, medical schools and communities of practice. In SNM, experimental projects in real-life contexts are seen to be critical by bringing together actors from variation and selection environments in shared networking and learning activities. In these experiments, firms, research institutes, universities and governments search and explore novel combinations and innovations and their social and institutional embedding. These experimental projects are often carried out at the local level though connected through trans-local communities of advocates, experts, networks of firms and policy-makers (Sengers and Raven, 2014).

Nonetheless, a key challenge that these niche experiments face concerns how to upscale successful innovations and practices beyond their initial limited context (Geels et al 2008). Whereas attention has been paid primarily to the roles of 'shielding' and 'nurturing', Smith and Raven (2012) argue that more focus should be given to the 'empowering' role of niches. "Shielding involves processes that hold off selection pressures in the context of multidimensional selection environments (industry structures, technologies and infrastructures,

\footnotetext{
${ }^{1}$ See Shove and Walker (2007) for a critique on the manageability of system innovation or transitions
} 
knowledge base, markets and dominant user practices, public policies and political power, cultural significance). Nurturing involves processes that support the development of pathbreaking innovation within passive and active shielded spaces through the development of shared, positive expectations, social learning and actor network building or the development of system structures and functions. Empowering involves processes that make niche innovations competitive within unchanged selection environments (fit and conform) or processes that change mainstream selection environments favourable to the path-breaking innovation (stretch and transform)”. (Smith and Raven 2012, p. 1034)

\section{Governance of system innovation}

An important unresolved issue concerns what role(s) the state could play when shielding, nurturing and empowering niche-level innovation. Some argue that niches are not created by governments but require instead experimentation with the distribution of responsibilities and the organization of relations between state, market, civil society and science and technology (Schot and Geels 2008). Others however assert that state action remains essential, as important processes implied by SNM can only be engineered through political support, and legitimized and enforced through the institutions of the state (Meadowcroft 2011). Ultimately, this question depends on what kinds of government and states are implied, foregrounding the importance of spatial contextualization and the characteristics of governance regimes (Coenen et al 2012). The concept of the embedded state (Evans 1995) is employed in this paper to discuss the mode of state engagement that seems most attuned to experimentation.

Evans (1995) argued that rather than debating 'how much' states intervene in society, it would be necessary to discuss different ways in which they intervene and the implications of these modes of engagement for society at large. Drawing on measures of bureaucratic autonomy, inspired by the work of Max Weber (Weber 1978), this line of work argues that 'good governance is based on the correlation between two variables: first is the professionalization of 
the public sector, which includes the quality of training and transparent measures for hiring and promoting staff. Second is the autonomy of the public sector from politicians. Here the goal is to have a balance between too little autonomy (excessive centralization which creates dependence on political cycles and smothers creativity) and too much autonomy (creates an unaccountable public sector, which looks after its own interests) (Evans 1995, Fukuyama 2013). This balance is called embedded autonomy, because 'bureaucrats need to be shielded from certain influences of social actors, but also subordinate to the society with regards to larger goals” (Fukuyama 2013, pp. 11).

The work of Evans (1995) on embedded autonomy is at the core of research on the embedded state, which aims to capture the interaction between organizational cultures within government and its relationships with the outside world (Jacobsson et al 2015). The concept of the embedded state can be deployed either as a research tool or as a normative guide. When applied as a research tool, it may describe the actual functioning of a state, comparing its internal organizational logic and structure with the relationships established with external stakeholders. In this sense, embeddedness refers to the porous boundaries of the state and the dynamic interaction between its internal resources and its networking practices.

In the normative version of the embedded mode which we are using here, the argument is that the state has a role to play in achieving economic or social progress, for example through its capacity to stimulate processes of 'self-discovery' (Hausmann and Rodrik 2003). These processes refer to incentives created by the state to help find new possibilities and solutions which have not yet been revealed. It does so by acting as a co-learner and its contribution depends on its problem-solving capabilities and competencies. The embedded state stands in contrast to the concept of the neoliberal state, which stresses an arm's length relationship between the state and other socio-economic actors. But it is also in contrast with dirigiste 
approaches, which underlie the "entrepreneurial state" discourse and which stress the role of the state as a more autonomous actor.

In terms of problem-solving, a policy perspective drawing on the embedded state as a tool to address system innovation goes beyond the neoclassical economics rationale that policy intervention is legitimate only in situation of market failure. Rather, it builds on the notion that policy intervention is legitimate and needed if the complex interactions that take place among the different organizations and institutions involved in innovation do not function effectively (Laranja et al 2008). Policies may ensure a sound functioning of innovation systems by creating and supporting infrastructure, institutions, interactions and capabilities (Woolthuis et al 2005), or they may be oriented towards system change in terms of correcting what Weber and Rohracher (2012) call transformational system failures:

1) Directionality failure: Lack of a shared vision/goal, and lack of coordination among actors.

2) Demand articulation failure: Demand restricted by insufficient information about user needs, a lack of public procurement signalling to shape demand, and a 'lack of demand articulation capabilities’ (the ability to signal the level/nature of demand)

3) Policy coordination failure: Lack of coordination between policy actors at different levels.

4) Reflexivity failure: Lack of monitoring, learning from, openly debating, and consequently adjusting policy support.

So far, these failures have primarily been developed and discussed at a conceptual level yet lack serious and systematic empirical investigation. This paper examines these transformational system failures by focusing on national conditions and policy abilities to respond effectively to the challenge of active ageing through assisted living experiments in the UK and Norway. 
Summarizing, this paper is concerned with system innovation, with a specific focus on assisted living technologies. Using the concept of SNM, our goal is to analyse how two different programmes in this area of activity have been implemented and, thus, govern system innovation. We are particularly concerned with the way in which these programmes have been capable of 'shielding', 'nurturing' and 'empowering' these emerging technologies and the social and institutional practices associated with them. We will also explore how different national state responses are embedded in society in order to deal with the systemic failures that need to be addressed in order for technologies to move from the niche to the regime level.

\section{Methodology}

The empirical analysis for this paper is supported by two case studies conducted in the period 2014-2016. The data collection was based on data triangulation between (a) desk-top research and document analysis, (b) interviews, and (c) participation in policy and industry seminars. The documents reviewed consisted primarily of collecting relevant material from government documents and policy reports, including evaluations of the policy programmes. For the second and most significant part of the research, interviews were conducted with key informants representing the policy apparatus, research and innovation policy programmes, interest organizations and municipalities. The interviews followed a semi-structured format, were conducted face to face, and were on average one hour long.

The interviews focused on the respondents' views on the development process within assisted living in particular, and with ageing policies in general. The topics covered included aspects such as coordination, collaboration, responsibilities, technologies, challenges, knowledge development and innovation. The semi-structured script was chosen to ensure that relevant topics were discussed, whereas at the same time allowing for unexpected aspects to arise during the conversation. The selection of respondents was initially based on contacting the central players in these programmes and later through a snowball approach where interviewees were 
asked to name potentially relevant candidates for subsequent interviews. The researchers took notes during the interviews and organized these notes according to the main themes, in order to compare and contrast the empirical material.

In the UK case, there were 20 interviews with stakeholders responsible for delivering ageing policies at the UK and Welsh levels, with representatives of Innovate UK, and with representatives of the four organizations supported by the Demonstrators of Assisted Living Lifestyles at Scale (DALLAS) programme (more detail about this programme is available in the results section). It also included attending seminars where results from DALLAS were announced and where they were discussed by a panel of practitioners and by academics responsible for evaluating the programme. In the Norwegian case, researchers conducted 20 interviews in 2014 and 2015 and attended 21 industry, policy and research gatherings (i.e. seminars, workshops, dialogue conferences, product presentations and conferences) in the period from 2011 to 2015. The seminars targeted different audiences and spanned various themes from technological products and solutions, innovation, public procurement practices, market opportunities around assisted living, policymaking and research.

\section{National systems of care and assisted living in the UK and Norway}

Responding to long-term trends associated with demographic ageing and an increase in chronic diseases, the national systems of care in the UK and in Norway are currently undergoing a major transformation regarding treatment and support for patients, particularly those in long-term care. This is the shift from treating and caring in hospitals, nursing homes and care homes, toward treatment and support in people’s own homes, utilizing assisted living technologies. However, the way in which this is being brought about differs between the two countries. In the UK, the delivery of services and support happens increasingly through the private market, which means a shift in public-provided care to provide greater personal choice (Mace 2014). In addition, there has been a progressive devolution of powers to the Scottish, Welsh and Northern 
Irish parliaments, which includes responsibilities over the health sector. The result is a high degree of fragmentation, including large organizations (particularly the state-run National Health Service (NHS)) and a multiplicity of smaller organizations and agents from the public, private and not-for-profit sectors, operating at different geographical scales.

In contrast to the UK, health care services in Norway primarily continue to be delivered through the public sector, and with still limited, although growing involvement of the private sector. In this model of welfare delivery (often referred to as the Nordic model) it is natural for the public sector to take a lead role in processes of innovation in health care. Nonetheless, central features of the Norwegian governance structure relate to a strong division between sectors as well as the importance of autonomous local government. Since the introduction of a legal act on autonomous local government in 1837 there has been a strong tradition for a locally anchored governance structure in Norway. This characteristic presents challenges in terms of policy fragmentation and coordination across the current 426 municipalities and 19 county municipalities. We therefore have two different contexts in regards to the importance and capacity of the public sector to act, though united in the persistence of fragmentation among its many partner organizations. This allows us to discuss the introduction of assisted living technologies, taking into account the significant institutional differences between the two countries.

\section{Assisted living in the UK}

In the UK the main institution funding the development of new technology and innovation in the field of assisted living is called Innovate UK (previously the Technology Strategy Board). Innovate UK is an executive, non-departmental public body, sponsored by the Department for Business, Innovation and Skills (BIS). It has since 2007 funded two major programmes in this area: the Assisted Living Innovation Platform between 2007 and 2012, and the DALLAS between 2012 and 2015. The latter is the one that we are using in this paper as a case study. 
Additionally, Innovate UK has funded other smaller projects in the area of assisted living through various funding streams.

Both programmes are part of a series of innovation platforms that Innovate UK has created, to foster innovation ecosystems in key sectors, where the challenges are both technological and institutional. These platforms are designed to be "safe spaces" (or niche experiments) where businesses, universities, governments and user communities can collaborate for mutually beneficial ends. The DALLAS programme was relatively unique as an instrument to stimulate innovation, because it was not intended to finance new technological development, but rather to upscale existing technologies. Upscaling in this context does not refer to national or system wide deployment, but rather increasing the number of users utilizing an existing technology. It was therefore about creating 'shielded' and ‘nurturing' environments, supported by local community groups and public financing, that would in theory help to 'empower' new technological solutions. In doing so, it put emphasis on the importance of building new relationships between stakeholders and on creating solutions that include end users through co-design.

From an analytical perspective, the DALLAS programme is an example of how a large organization (Innovate UK) can use its resources to support niche activity that has the potential to address some systemic failures (see table 1 for a summary of results regarding SNM). The level of funding and the time span of three years, created a shielded and nurturing environment where organizations could adopt ambitious co-design, or user-led design projects. The latter were based on the ambitious target of involving over 100,000 end-users across the 4 projects, plus clinicians, health experts, carers, health organizations, SMEs and other relevant stakeholders in the design and delivery of new products services. This strategy was designed to ensure that the outputs were aligned with user needs, that they helped to reduce scepticism towards their use and helped to encourage health professionals to change 
their practices and to consider the prescription of these technologies as part of their daily routine. The shielding is ensured by protecting the project from selection mechanisms, either in the market or in the public sector bureaucracy, at least for the period of its duration.

The DALLAS project relied heavily upon a market based approach, which adds to the multiple, and often contradictory, processes of decentralization and outsourcing to the private or third sectors that characterizes the UK health system. This outsourcing, which happened in this programme through a call for tender to which external organizations replied, means that the state does not commit to upscaling successful technologies at a later stage to the national level. In turn, the expectation is that if these technologies are indeed successful, they should become dominant through market selection mechanisms.

Table 1 here

\section{Assisted living in Norway}

The case study discussed in the Norwegian context is the national programme for welfare technologies (SAMVEIS). The programme was launched in 2013 by the Norwegian Directorate of Health, an executive agency subordinate to the Norwegian Ministry of Health and Care Services. Its overall aim is to ensure that such technologies shall be part of public health care services by 2020. In order to do so, the main tasks are to test and develop assisted living technologies and services in the municipalities; to generate and diffuse knowledge on assisted living; to develop good models for the introduction and use of assisted living technologies; and to develop standards and IT architecture on assisted living technologies. The national programme for welfare technologies is primarily directed towards the municipal health care services, but will nonetheless also contribute to an increased use of assisted living technologies in the specialized health services at the national level and in the private sphere. 
So far, the government's attention has largely been directed at testing assisted living technologies. These include digital sensors, digital alarms, person tracking systems and safety systems. Through the provision of financial support and expertise, the aim is to encourage municipalities to test such technologies in patients' homes, in specialized apartments, or when renovating or building new care facilities. In terms of timeline, the SAMVEIS programme consists of four phases:

- Establishment and preparations: 2013-2014

- Testing 2014-2016: The testing phase is to run until mid-2016 and its objective is to generate experiences and to develop methodologies and practical tools and service models. It also intends to provide training for the municipalities, to assist them in implementing solutions using these technologies.

- Upscaling 2015-2020: The programme is planning to involve 320 municipalities in the upscaling stage by 2019. The aim is that by $202080 \%$ of the population shall have access to welfare technologies.

- Consolidation 2020: The objective for the consolidation phase is to ensure usage of the solutions based on welfare technologies by the end of the programme period.

As part of the initial test phase the programme has funded 10 pilot projects involving 31 municipalities (out of 426 nationally). Since the launch in 2013 the pilot programme has had a budget of approximately 3.5 million Euros annually, which ran in parallel with other government funds covering active ageing. All the municipalities that were included in the programme were also part of a network to facilitate knowledge exchange, coordinated by the Norwegian Directorate of Health and the association of local and regional governments. The participants in the programme were expected to report on their activities with other municipalities, both within and beyond the boundaries of SAMVEIS. Additionally, one of the 
national centres for care research was commissioned with the tasks of running a research network and of synthesizing and communicating research results from the programme.

When interpreted through the conceptual lens of SNM, the SAMVEIS programme can be seen as an example of protected niche development, anchored in the existing health care regime (see table 1). The national policy programme has provided resources and legitimacy, which in turn have carved out an incubation space that is partly shielded from competition and selection criteria in the established care system. It has therefore created the conditions for 'shielding' a new socio-technical approach to active ageing. At the same time the programme nurtured new technological development by implementing an architecture and standards for the new health care regime through the use of the Continua standard. Also, because it is a national programme, it included mechanisms to create an innovative platform involving various stakeholders across public, private and civic sector and to combine supply side and demand side innovation policy measures. It has also sought to stimulate collaboration and interaction with subcontractors, users and their next-of-kin that was conducive to increasing the alignment of emerging and immature technologies with values, norms and practices in care provision. Both these elements, technological interoperability and extended networks, could serve as the basis for 'empowering' measures, which are expected to take place in the upscaling and consolidation stages of the programme.

\section{Comparative analysis of governance approaches}

As these programmes highlight, such development processes of SNM include complex and integrated systemic challenges that cover both technological development and standardization, alignment with existing health care services, changes in organizational and social routines and practices, as well as the challenge of joint learning across several stakeholders throughout the different phases. We will focus here on how the states of the UK 
and Norway dealt with these issues, drawing on the typology of systemic failures by Weber and Rohracher (2012).

\section{Directionality}

According to the project evaluation (Devlin el al 2016), to interviews with representatives from the four projects, and to the results discussed at the final seminar organized by Innovate UK, the DALLAS programme was fairly successful in addressing directionality and demand articulation failures, but less so in addressing policy coordination or reflexivity failures (see table 2 for a summary). The first (directionality) was addressed through a bottom-up strategy which brought together a significant group of actors to work on a project with clearly defined aims, thereby allowing for the development of a shared goal. By also providing public funding that can compensate for the lack of private sector investment, these goals were to a large extent achieved. There were however several important challenges at the early stage of implementation, which highlight the difficulties in nurturing new relationships at this level. First, was the difficulty of working across sectors, due to different organizational cultures. For example, Devlin et al (2016) contrast the experience of the third sector in working with grassroots initiatives, which tend to be time consuming, versus the experience of technological firms of focusing on efficient product development (which implies avoiding excessive delays). The same authors also refer to initial difficulties of different partners in understanding what was legally required of them. This problem was made worse due to austerity policies, which made several partners fearful that this programme would be an excuse for further cutbacks.

Table 2 here 
Finally, both the evaluation and the interviews with representatives revealed that the organizational culture of the NHS and its size worked as an impediment to change. Nonetheless, Devlin et al (2016) argued (a view also supported by the representatives of each project that were interviewed) that the existence of government funds, which provided financial incentives, a medium time horizon, and the fact that these were bottom-up projects, allowed for trust to be built among partners. The last point was an important achievement because one of the major hindrances identified by the leaders of these four projects was the conservatism of health experts. Their attitudes are partly the result of experimentation exhaustion, as experts go through several rounds of testing new technologies or approaches but rarely see results. However, they also related to the difficulty in enacting regime change, as large organizations such as the NHS tend to experience high levels of inertia and to favour stability rather than change. This is particularly true in the aforementioned context of austerity and financial cuts. These projects were capable of delivering change in this area by first engaging with early-adopters among the health experts. When results emerged, other experts were brought on board, either through peer-pressure (doctors advising other doctors to experiment with a new technology) or end-user pressure (as patients hear about a new technology and ask about it for themselves).

As opposed to the bottom-up character of the DALLAS programme, in the Norwegian case, directionality was addressed through a pro-active and top-down approach, as the result of the leadership of the Norwegian Directorate of Health and the Association of local and regional authorities. Admittedly, prior to the establishment of the national policy programme SAMVEIS many municipalities had already taken some initial bottom-up steps towards testing new technological solutions, in small-scale pilot projects in advance of the launch of the national policy programme. Still, the establishment and testing phases of SAMVEIS can 
primarily be characterized as top-down in the sense that the state has been heavily involved in shaping the issues of directionality and demand articulation.

It did this in a variety of ways: first, the government took a lead role by setting the agenda and pointing out the direction and long term goals that welfare technologies shall be an integrated part of public health care services by 2020. Second, the state was proactive in establishing the policy programme and initiating the ten pilot projects. Third, it defined the needs and technologies to be developed and tested out. Fourth, it initiated joint activities and networks to ensure interaction and learning across the projects and between municipalities, industry and users. And fifth, it used a technological standard to ensure interoperability and to stimulate competition and establish a market.

The importance of the state in this process suggests that transition processes may need strong leadership to initiate and guide the process. This is in line with the argument of Shove and Walker (2007), according to whom the governance of transition processes cannot be fully understood as a self-organizing process. The adoption of a top-down approach was furthermore justified by the previous experience of Denmark, where the "Welfare technology funds” from 2008 was liquidated due to coordination challenges across a multitude of fragmented and smaller projects.

\section{Demand}

Regarding demand articulation failures, DALLAS dealt with two of the most important failures in the current system: the lack of knowledge among users and health experts about the benefits of new technologies or services, and the lack of technological literacy that would allow patients to use these technologies. This is particularly the case for elderly patients who struggle to use ICTs more effectively. The emphasis on co-design and the involvement of a large number of end users contributed, even if only slightly, to address both issues. This 
process can however have powerful self-reinforcing effects, since as a technology diffuses through the community it encourages uptake even among those who are not involved in the project. On a different level, one of the projects funded by this programme contributed to address this systemic failure by encouraging interoperability between technologies, which is one of the main barriers to achieve higher demand, scale economies and lower costs.

In a similar way, in order to facilitate the emergence of a market for assisted living technologies and thereby increase demand, the Norwegian Directorate of Health applied the Continua framework. Continua is an international alliance which works towards the definition of standards to ensure technological interoperability, as it creates the conditions for the development of diverse technological solutions based on the same basic IT architecture. Continua was a recommended standard from 2016, and will be made compulsory from 2019. After the initial focus on technical standardization, the programme has increasingly emphasized the importance of standardizing services, by developing guidelines for various kinds of assisted living services associated with different types of municipal characteristics and needs.

\section{Coordination}

The main shortcomings in the UK were at the level of vertical and horizontal policy coordination and reflexivity. The failures in vertical policy coordination arise because though these projects are successful within their own environment (according to the evaluation provided by DALLAS and the interpretation of representatives from the four projects), the regime in the UK lacks intermediary organizations or the political will to upscale and disseminate good results. While discussing the achievements and strengths of their projects, the representatives of these four initiatives consistently referred to the NHS as an external organization that prevents change, rather than a partner or even an interested party. 
Also at the level of vertical policy coordination, system change is blocked by the fact that community based health initiatives tend to rely on funding from municipalities. This presents two set of problems, according to experts interviewed working in ageing issues both in Wales and in England: on the one hand, local authorities in the UK continue to have limited financial and administrative autonomy and are dependent on funding decisions from central government. On the other hand, new approaches to assisted living tend to privilege care and prevention, which has positive effects in terms of reducing hospital admissions and the need for expensive surgeries (such as hip replacement surgeries). These savings however are felt in the health budget and not in the local authorities’ budget, which are in fact financing such initiatives. Therefore, the lack of policy coordination creates perverse incentives, where the organizations making the investments are not the ones benefiting financially.

In terms of horizontal coordination, these projects reveal shortcomings due to fragmentation between organizations and agents. Policy in the field of assisted living in the UK (and in health in general) continues to be directed through a silo-based approach. This is highlighted by the fact that this programme was funded by Innovate UK, an agency affiliated to the Department for BIS, rather than the Department of Health. This means that even if it is successful, it is not strictly health policy but economic policy. This in turn clashes with the sweeping health reforms which the current government has been trying to implement, through its health secretary, and which have in themselves been heavily discussed and revised as a result of ongoing criticism from multiple stakeholders.

In Norway, SAMVEIS constituted an important coordinating mechanism across the fragmented municipal landscape, though there were important shortcomings. According to the subcontractors, there has been a lack of knowledge among the municipalities about existing solutions within welfare technologies and the implications and use of these. Such a view is also confirmed by respondents in the municipalities and illustrates that it is costly and 
demanding to be up to date with the (national and international) developments in this field, and which highlights the need for pro-active governance and policy coordination. Overall, the data collection and analysis revealed that there are still unresolved coordination issues, particularly across the following areas of activity:

- Across science driven and practice oriented knowledge development;

- Across the research activities following the ten pilot projects;

- Across relevant public sector stakeholders at various governance levels;

An example of the latter point is the fact that NAV, the Norwegian national health service, was not included in SAMVEIS, even though it is the national body responsible for the technical aid apparatus and for providing home-based care services. This may represent a challenge during the last stages of upscaling and consolidation of the policy programme.

The strengths and shortcomings of SAMVEIS are to a significant extent a product of how the Norwegian state embeds itself within society, and which in turn shapes how it deals with transformational system failures. The dual tradition of centralized welfare state provision and strong, autonomous local government, creates opportunities for the central state to push for the development of applied solutions in a context of technological uncertainty, while relying on decentralized power structures. This implies balancing between an embedded and a dirigiste governance mode in terms of a top-down governance allowing for local experimentation, involving municipalities, partners in the private sector, health experts and end-users.

The downside is that a strong centralized state often finds it difficult to coordinate with different levels of government and to learn from bottom up-experience. In this case, policy coordination has primarily been oriented upstream in terms of initiating the ten pilot projects, but less has been done in terms of learning from the experiences generated across the pilot 
projects. Also, due to dissatisfaction with the number of test users in the municipal pilot projects, the Norwegian Directorate of Health has been searching for different solutions, independently from the results and experiences generated in the pilot projects. Therefore, the coordination and upscaling of the experiences from the pilot projects beyond the niche level have during the initial phases been scarce, though it will be necessary to wait for stages three and four to reach final conclusions.

\section{Reflexivity}

The policy coordination shortcomings identified in the UK context compound problems of reflexivity failure. Though Innovate UK is attempting to maintain a learning community in this area, by supporting DHACA (2016), its activities continue to depend on bottom-up initiatives, and have not led, up to this point, to reflection and debates at the national level. The fact that these are project based activities, funded for a specific period of time, also hinders future learning, since no organization is responsible for taking its lessons forward and implementing them widely. In the case of Norway the Norwegian Directorate of Health attempted to deal with this issue through information meetings and seminars for learning and knowledge exchange between municipalities, subcontractors and other relevant stakeholders. However the learning process has fallen short of expectations. As an example, the first meeting of the research network responsible for evaluating results only took place two years after the launch of the national programme. This signals a somewhat limited effort and ambition in terms of ensuring continuous learning, reflexivity and diffusion across the involved stakeholders in the programme.

Also, there were complaints among the researchers who followed the pilot studies that there was no process of calibration of expectations among subcontractors, municipalities (and users) in the early phases of the pilot projects. According to these informants, such a 
calibration process could have established trust between the involved stakeholders, in addition to clarifying roles, objectives and avoided false expectations and misunderstandings.

Moreover, the efforts of joint testing and knowledge generation in the pilot projects have so far been primarily practice-oriented and largely directed towards the municipalities, and weakly connected to the remaining national science-based, knowledge development infrastructure in the Norwegian Research Council (HelseOmsorg21 2014). In sum, these factors suggest a lack of coordination and reflexivity.

\section{Summing up of findings}

Before we outline our theoretical conclusions, we would like to highlight the main similarities and differences between the case studies. In both the Norwegian and UK case, state supported and funded niche experimentation has been instrumental in designing and implementing system innovation, either through a top-down (in Norway) or bottom-up fashion (UK). More importantly, these projects have contributed to the identification and articulation of the various systemic barriers that impede the wider diffusion of assisted living technologies among a broad range of stakeholders. Through their emphasis on co-design and co-creation, these projects demonstrated the value of early implementation pilots to explore the 'fit' between novel technologies and prevailing practices and institutional structures in national systems of care.

They also demonstrated that a relatively sharp distinction drawn between social and technological innovation is not very productive, as the implementation of assisted living technologies necessarily involves both. An implication of both cases is that national rules and regulations need to foster rather than frustrate local experimentation along the lines suggested by proponents of experimentalist governance (Sabel and Zeitlin, 2012). These projects show that experimentation is in fact allowed to happen at the niche level, through either bottom-up tendering or top-down pilot projecting, with the main barriers emerging at the empowerment 
stage. In this sense, the cases have highlighted the importance of coordinating mechanisms in the governance of system change.

Empowerment would require reflexivity and policy coordination, which are in these particular cases in conflict. In the UK case study, the small scale of projects and their project based funding encourages a type of reflexivity restricted to the evaluation of outcomes and it is not supported by the existence of mediating public sector organizations that could link its results to reforms in the health sector. This reinforces policy silos and frustrates coordination across policy domains. In the Norwegian case, the centralized approach could in principle facilitate policy coordination, except that the underlying tensions between local and central government challenges synchronization and coordination. These would be necessary to produce practice based learning and to identify appropriate paths towards upscaling and system change. One can therefore argue that for both countries, reflexivity and a capacity and willingness to learn from experiments (i.e. to learn from experience and mistakes) remain limited to project-based (internal) learning.

The cases were most strikingly different in terms of addressing the transformational system failure concerning directionality. In Norway, the state took a lead role and pointed out explicitly the direction of search in finding solutions to address active and healthy ageing. It clearly set an agenda and provided a roadmap for assisted living technologies (e.g. by relating it to international technological standards in the Continua platform). The rationale for doing so has been to ensure interoperability and thereby competition between different solutions in order to secure innovation and scalability in the pilot projects. In the UK, there was far less guidance concerning directionality as the programme was largely designed to facilitate bottom-up, community based responses and initiatives. As a result, pilot projects were internally guided by committed individuals and organizations with a clear, shared vision of goals and aims, but without a bridging mechanism to achieve overall coordination. In simple terms, one could argue 
that the Norwegian case was better at achieving coordination, while the UK case had a broader inclusion of various user groups and stakeholders in the niche projects. In Norway there was limited participation from test users, NGO's and other types of stakeholders. The Norwegian state might eventually prove to be better at upscaling to the national level, if stages three and four are successful. No comparative stages are predicted in the UK.

\section{Conclusions}

The aim of this paper has been to identify and understand different approaches to governing system innovation by comparing state responses to assisted living in two contrasting national systems of care, namely that of the UK and Norway. In order to shed light on these issues we have applied theorizing on strategic niche management, the embedded state and transformational system failures. We will now draw some theoretical conclusions from our empirical analysis.

The paper has shown how the societal challenge of ageing and the development of assisted living technologies imply adjustments at the technological, organizational, institutional or social levels. Through the analysis and discussions of the two cases we have arrived at a closer understanding of the relation between the notions of shielding, nurturing and empowerment in SNM on the one hand, and the four transformational system failures (directionality, demand, coordination and reflexivity) on the other. The paper has illuminated how governing system innovation needs to provide the three SNM stages (i.e. shielding, nurturing and empowering) with directionality and (societal) demand articulation, as well as ensuring a continuous coordination and reflexivity across the three governance phases. The integrated and systemic character of such development processes requires several roles and functions from government.

In addition, these findings point out the limitations of the concept of the embedded state for governing system innovation. The concept is appealing, with its attempt to address the decades- 
old debate between government and market failures by suggesting a networked and reflexive approach to policy making (Hausmann and Rodrik 2003). But in doing so it sidesteps important elements of state theory, namely the inherent tensions between different levels of government and between government and outside influences. Though coordination and reflexivity are possible and needed elements in policy-making, it should not be ignored that competition, biases or conflicting interests are also at its core, and will influence outcomes (Sabatier 1999). This is particularly the case when conflicts emerge between well-established agents and institutions of an existing regime, and niche solutions whose efficacy remains relatively untested and which involve a combination of new technical, social, organizational and institutional solutions.

The use of the concept of the embedded state in a normative sense is even more problematic. The work of Hausmann and Rodrik (2003) does corroborate the importance of the state in initiating cycles of technological progress and growth, but these authors are mostly referring to policies which aim to generate incentives to investment (e.g. subsidies or trade tariffs). However, the concept of the embedded state which is found in current innovation policies at the EU level (Morgan 2016) anticipates a far more activist state, capable of creating and animating networks, helping to decide on strategic investments and finding a balance between centralized decision-making and decentralized action. This is a far more demanding set of tasks and there is not sufficient evidence to suggest that it can be done. This normative view also does not address issues of accountability and transparency in policy making (Bovens 2007). For example, how can one distinguish a priori nurturing and shielding practices which facilitate the development of essential technologies, from those which are deployed to protect special interests?

These limitations raise issues for future research. Closer attention needs to be paid to experimental governance, as illustrated in this paper. There is a need for a finer understanding 
as to how local projects can be amplified beyond their local domain to address and tackle grand challenges at the system level. A potentially promising approach to address this question is through a perspective of embedded agency. Such an approach would help to investigate how place-based projects of experimental governance in socio-technical transitions become vehicles of institutional entrepreneurship. This would require more comparative research of experimental governance across different sectors, regions and nations.

\section{Acknowledgements}

The authors would like to acknowledge the insightful feedback from participants at the 2015 Annual Conference of the EU-SPRI Forum.

\section{Funding}

This project has received funding from the European Union's Seventh Framework Programme for research, technological development and demonstration under grant agreement no 320131 (SmartSpec).

\section{References}

Benner, M. (2014). From smart specialisation to smart experimentation. Zeitschrift Für Wirtschaftsgeographie, 58(1), 33-49.

Bovens, M. (2007). Analysing and Assessing Accountability: A Conceptual Framework. European Law Journal, 13(4), 447-468.

Bulkeley H, Broto VC and Edwards G. (2012) Bringing climate change to the city: towards low carbon urbanism? Local Environment 17: 545-551. 
Coenen L, Benneworth P and Truffer B. (2012) Toward a spatial perspective on sustainability transitions. Research Policy 41: 968-979.

Coenen L, Raven R and Verbong G. (2010) Local niche experimentation in energy transitions: A theoretical and empirical exploration of proximity advantages and disadvantages. Technology in Society 32: 295-302.

Devlin, A. M., McGee-Lennon, M., O’Donnell, C. A., Bouamrane, M.-M., Agbakoba, R., O’Connor, S., Grieve, E., Finch, T., Wyke, S., Watson, N., Browne, S., Mair, F. (2016). Delivering digital health and well-being at scale: lessons learned during the implementation of the dallas program in the United Kingdom. Journal of the American Medical Informatics Association, 23(1), 48-59.

DHACA (2016) Digital Health and Care Alliance. Available at: http://dhaca.org.uk/.

Evans, P. (1995). Embedded autonomy: states and industrial transformation. Princeton: Princeton University Press.

Fukuyama, F. (2013). What Is Governance? (Working Paper 314). Center for Global Development, Washington D.C.

Geels, F.W. 2002. Technological transitions as evolutionary reconfiguration processes: a multilevel perspective and a case-study. Research Policy 31:1257-1274.

Geels FW, Hekkert MP and Jacobsson S. (2008) The dynamics of sustainable innovation journeys. Technology Analysis \& Strategic Management 20: 521-536.

Hausmann R and Rodrik D. (2003) Economic development as self-discovery. Journal of Development Economics 72: 603-633. 
HelseOmsorg21. (2014) Et kunnskapssystem for bedre folkehelse. Nasjonal forsknings- og innovasjonsstrategi for helse og omsorg: Research Council of Norway.

Hirschman, A. (1958) The Strategy of Economic Development, Yale University Press, New Haven

Jacobsson, B., Pierre, J., \& Sundström, G. (2015). Governing the Embedded State: The organizational dimension of governance. Oxford: Oxford University Press.

Jensen MB, Johnson B, Lorenz E, et al. (2007) Forms of knowledge and modes of innovation. Research Policy 36: 680-693.

Kemp R, Schot J and Hoogma R. (1998) Regime shifts to sustainability through processes of niche formation: The approach of strategic niche management. Technology Analysis \& Strategic Management 10: 175-198.

Laranja M, Uyarra E and Flanagan K. (2008) Policies for science, technology and innovation: Translating rationales into regional policies in a multi-level setting. Research Policy 37: 823835.

Mace, A. (2014) Long-Term Care in the UK, Department for Business, Innovation and Skills, London

Martin, B.R. (2015) Twenty Challenges for Innovation Studies. SPRU Working Paper Series SWPS 2015-30 (November), SPRU Science Policy Research Unit / University of Sussex.

Meadowcroft J. (2011) Engaging with the politics of sustainability transitions. Environmental Innovation and Societal Transitions 1: 70-75. 
Morgan, K. (2016) Speaking Truth to Power: The Political Dynamics of Public Sector Innovation, in D. Kyriakou, M. Palazuelos Martínez, I. Periáñez-Forte and A. Rainoldi (eds) Governing Smart Specialisation, Routledge, Abingdon.

OECD (2015) System Innovation: Synthesis Report, OECD, Paris

Sabatier, P. A. (1999) Theories of the policy process. Theoretical lenses on public policy. Book, Boulder, Colo.: Westview Press.

Sabel, C. and J. Zeitlin (2012) Experimentalist Governance, in D. Levi-Faur (ed) The Oxford Handbook of Governance, Oxford University Press, Oxford, p. p. 169-185

Schot J., Geels FW. (2008) Strategic niche management and sustainable innovation journeys: theory, findings, research agenda, and policy. Technology Analysis \& Strategic Management 20: 537-554.

Sengers, F., \& Raven, R. (2014) Metering motorbike mobility: informal transport in transition? Technology Analysis \& Strategic Management, 26(4), 453-468.

Seyfang, G., Smith, A (2007) Grassroots innovations for sustainable development, Environmental Politics, 16:4, pp. 584-603

Shove, E., Walker, G. (2007) CAUTION! Transitions ahead: politics, practice, and sustainable transition management. Environment and Planning A 39:763-770.

Smith, A., Voß, J-P., and Grin, J. (2010) Innovation studies and sustainability transitions: The allure of the multi-level perspective and its challenges. Research Policy 39: 435-448.

Smith A., Raven R. (2012) What is protective space? Reconsidering niches in transitions to sustainability. Research Policy 41: 1025-1036. 
Steward F. (2012) Transformative innovation policy to meet the challenge of climate change: sociotechnical networks aligned with consumption and end-use as new transition arenas for a low-carbon society or green economy. Technology Analysis \& Strategic Management 24: 331343.

Tinker, A., Kellaher, L., Ginn, J. and Ribe, E. (2013) Assisted Living Platform - The Long Term Care Revolution, TSB, Swindon

Weber, M. (1978). Economy and Society. London: University of California Press.

Weber, K., Rohracher, H. (2012) Legitimizing research, technology and innovation policies for transformative change, Research Policy, 41(6), 1037-1047

Woolthuis, R.K., Lankhuizen, M., Gilsing, V.A., 2005. A system failure framework for innovation policy design. Technovation 25, 609-619. 
Table 1 - Shielding, nurturing and empowering processes in assisted living programmes in UK and Norway

\begin{tabular}{|c|c|c|c|}
\hline Country (Programme) & Shielding & Nurturing & Empowering \\
\hline United Kingdom (DALLAS) & $\begin{array}{l}\text { Significant levels of funding for } \\
\text { three years - focus on building } \\
\text { relationships and improving existing } \\
\text { technologies rather than } \\
\text { development of new products }\end{array}$ & $\begin{array}{l}\text { The time span of three years } \\
\text { allowed each project to overcome } \\
\text { initial reluctance or different } \\
\text { organisational practices and forge } \\
\text { new relationships }\end{array}$ & $\begin{array}{l}\text { Limited - no connections between } \\
\text { Innovate UK and other government } \\
\text { agencies or ministries to upscale; } \\
\text { Innovate UK supports a digital } \\
\text { network DHACA }\end{array}$ \\
\hline Norway (SAMVEIS) & $\begin{array}{c}\text { Involvement of Norwegian } \\
\text { Directorate of Health guarantees } \\
\text { financial and political support; focus } \\
\text { on developing and testing new } \\
\text { solutions of assisted living }\end{array}$ & $\begin{array}{c}\text { Use of Continua framework to } \\
\text { ensure interoperability; multiple } \\
\text { networks built to facilitate } \\
\text { interaction and communication } \\
\text { between partners }\end{array}$ & $\begin{array}{l}\text { Upscaling stage currently in } \\
\text { progress; evidence of some } \\
\text { fragmentation but involvement of } \\
\text { central government intended to } \\
\text { guarantee upscaling }\end{array}$ \\
\hline
\end{tabular}


Table 2 - Transformational system failures and assisted living programmes in Norway and UK

\begin{tabular}{|l|c|c|c|c|}
\hline Country (Programme) & Directionality failure \\
system failures & Demand articulation failure & Policy coordination failure & Reflexivity failure \\
\hline United Kingdom (DALLAS) & $\begin{array}{c}\text { Bottom-up projects by third- } \\
\text { sector partners ensure focus } \\
\text { and coherence; existence of } \\
\text { three year funding provides } \\
\text { incentive to other partners }\end{array}$ & $\begin{array}{c}\text { Creates technological } \\
\text { literacy among potential } \\
\text { end-users; one project } \\
\text { specifically about } \\
\text { interoperability }\end{array}$ & $\begin{array}{c}\text { Fail vertically due to lack of } \\
\text { coordination between scales } \\
\text { of government; fail } \\
\text { horizontally due to lack of } \\
\text { involvement from NHS, } \\
\text { other government } \\
\text { departments }\end{array}$ & $\begin{array}{c}\text { Lack of continuity (apart } \\
\text { from DHACA website) } \\
\text { limits opportunities for } \\
\text { learning and reflexivity }\end{array}$ \\
\hline Norway (SAMVEIS) & $\begin{array}{c}\text { Pro-active, top down } \\
\text { approach from Norwegian } \\
\text { Directorate of Health and } \\
\text { Association of local and } \\
\text { regional authorities provides } \\
\text { guidance and coherence }\end{array}$ & $\begin{array}{c}\text { Definition of clear long term } \\
\text { goals for welfare } \\
\text { technologies; selection of } \\
\text { specific technologies, use of } \\
\text { Continua framework to } \\
\text { ensure interoperability }\end{array}$ & $\begin{array}{c}\text { Vertical and horizontal policy } \\
\text { coordination by national } \\
\text { agency in the programme. } \\
\text { Still some fragmentation } \\
\text { across government levels } \\
\text { and across stakeholders in } \\
\text { knowledge development }\end{array}$ & $\begin{array}{c}\text { Monitoring and } \\
\text { evaluation limited and } \\
\text { happening at arm's } \\
\text { length; few end users in } \\
\text { first phases; limited } \\
\text { ambitions and continuity } \\
\text { in reflexivity }\end{array}$ \\
\hline
\end{tabular}

